\title{
PENGARUH PERAN AKTIF KADER KESEHATAN TERHADAP KUNJUNGAN NEONATUS LENGKAP DI POSYANDU DESA TIMBANGREJA WILAYAH KERJA PUSKESMAS LEBAKSIU KABUPATEN TEGAL
}

\author{
Ike Putri Setyatama ${ }^{1}$ \\ Dosen Program Studi DIII Kebidanan STIKES Bhamada Slawi, Kabupaten Tegal \\ ${ }^{1}$ Email/cp: ike.putri.nugraha@gmail.com/08985915665
}

\begin{abstract}
ABSTRAK
Di Kabupaten Tegal pada tahun 2017 terjadi 171 kematian neonatal dan puskesmas yang paling rendah cakupan kunjungan neonatus lengkapnya adalah puskesmas Lebaksiu, dimana tahun 2015 kunjungan neonatus lengkap 96,7\%, di tahun 2016 kunjungan neonatus lengkap 96,2\% dan pada tahun 2017 terjadi angka penurunan kunjungan neonatus lengkap yaitu 77,7\% dimana target dari kunjungan neonatus lengkap yaitu 88\% (Dinkes Kab Tegal,2017). Di Puskesmas Lebaksiu jumlah kader kesehatan seluruhnya ada 285 orang tetapi yang aktif hanya 243 orang $(85 \%)$ dan terdapat satu desa dengan keaktifan kader paling rendah adalah desa Timbangreja dengan 67\%, dimana kader terbilang aktif jika memenuhi target $80 \%$ sehingga hasil tersebut belum mencapai cakupan keaktifan kader.

Tujuan penelitian ini untuk mengetahui Pengaruh Peran Aktif Kader Kesehatan Terhadap Kunjungan Neonatus Lengkap Di Posyandu Desa Timbangreja Wilayah Kerja Puskesmas Lebaksiu Kabupaten Tegal Tahun 2018. Desain penelitian: penelitian kuantitatif dengan metode survey, dan pendekatan retrospektif. Populasi dalam penelitian ini berjumlah 30 orang, yaitu kader kesehatan yang bertugas di desa Timbangreja wilayah kerja Puskesmas Lebaksiu. Penelitian ini mengunakan total samplimg, sehingga seluruh populasi merupakan sampel penelitian. Data yang digunakan adalah data sekunder jumlah kehadiran kader kesehatan dan jumlah kunjungan neonatus dalam setahun.

Berdasarkan perhitungan Kendall'stau dengan $\alpha=0,05$ diperoleh nilai p sebesar 0,04, koefisiensi korelasi 0,536; artinyaHubungan peran aktif kader dengan kunjungan neonatus lengkap adalah signifikan, kuat dan searah. Hasil uji statistik pengaruh dengan Regresi Logistik, diperoleh nilai Sig. 0,007, hal tersebut berarti ada pengaruh peran aktif kader kesehatan terhadap kunjungan neonatus lengkap di Posyandu Desa Timbangreja wilayah kerja Puskesmas Lebaksiu Kabupaten Tegal tahun 2018, dan kedua varibel tersebut saling mempengaruhi, dengan nilai B sebesar 12,6 yang berarti bahwa kader yang aktif akan berpengaruh 12,6 kali lebih besar terhadap kelengkapan kunjungan neonatus.
\end{abstract}

Kata kunci : Kader kesehatan, Kunjungan Neonatus Lengkap

\section{ABSTRACT}

In 2017, there were 171 neonatal death in Tegal regency and puskesmas that was the lowest coverage of complete neonatal visit was puskesmas of Lebaksiu; in 2015 the complete neonatal visit was $96.7 \%$, 96.2\% in 2016 and in 2017 there was a decline rate of complete neonatal visit numbered $77.7 \%$ where the target of complete neonatal visit was $88 \%$. In Puskesmas of Lebaksiu, there were 285 health cadres but only 243 persons $(85 \%)$ had an active role. Timbangreja village was a village having the lowest active role of the health cadres numbered $67 \%$, where cadres were said as active cadres if it fulfilled the target of $80 \%$ so that cadres in Timbangreja were not mentioned as active cadres yet.

Formulation of the problem in the study was how the effect of the active role of health cadres to a complete neonatal visit at Posyandu Timbangreja village in Puskesmas of Lebaksiu Tegal Regency in 2018. The research objective was to find out the effect of the active role of health cadres to a complete neonatal visit at Posyandu Timbangreja village in Puskesmas of Lebaksiu Tegal Regency in 2018. Research design was quantitative with survey and retrospective approach. The population was 30 health cadres who were on duty at Timbangreja village in Puskesmas of Lebaksiu. The research used total sampling so that the population was also research sample. The used data were secondary data of number of attendance and number of neonatal visit in a year. 
Based on the calculation of Kendall'stau with $\alpha=0.05$, $p$ value was 0.04 , and correlation coefficient of 0.536 . It statistically means that there was a significant, strong, and directed relationship between the active role of health cadres and a complete neonatal visit. The sig. value of logistic regression was 0.07 ; it showed that there was an effect of the active role of health cadres to a complete neonatal visit at Posyandu Timbangreja village in Puskesmas of Lebaksiu Tegal Regency in 2018. The two variables influenced each other with B value of 12.6; it means that active health cadre had 12.6 times greater on the neonatal visit.

Keywords : Health Cadres, Complete Neonatal Visit

\section{Latar Belakang}

Tren Angka Kematian Bayi (AKB) yang terus meningkat merupakan suatu permasalahan besar bagi suatu negara, dikarenakan AKB ini merupakan indikator yang mencerminkan tingkat pembangunan kesehatan dan kualitas hidup masyarakat dari suatu negara. Sejak 2015 lalu, dunia mulai bekerja keras ke arah agenda pengembangan global yang baru, yaitu Suistainable Development Goals (SDG's). Ini bertujuan untuk menurunkan AKB sekurangkurangnya 12/1.000 kelahiran hidup pada 2030 (Kemenkes RI, 2015).

Menurut Kementrian Kesehatan RI (2016), Angka Kematian Neonatal (AKN), Angka Kematian Bayi (AKB) dan Angka Kematian Balita (AKABA) merupakan indikator angka kematian yang berhubungan dengan anak. Kematian neonatal memiliki kontribusi terhadap kematian sebesar 59\% di usia 0-28 hari (Kemenkes RI, 2016).

Berdasarkan data Survei Demografi dan Kesehatan Indonesia (SDKI) 2012, angka kematian bayi di Indonesia menurun dari 2007, yaitu dari 34 per 1.000 kelahiran hidup menjadi 32 per 1.000 kelahiran hidup, hal ini masih belum mencapai target SDG's pada tahun 2030. Berarti 1 dari 31 bayi meninggal sebelum mencapai usia 1 tahun. Sebanyak $60 \%$ kematian bayi terjadi pada usia 0 bulan dan $80 \%$ kematian balita terjadi pada umur 0-11 bulan. Hal ini menjadi tantangan besar bagi Indonesia untuk menurunkan angka kematian bayi (Kemenkes RI, 2012).

Angka kematian neonatus di Indonesia tahun 2015 yaitu 33.278 per 100.000 kelahiran hidup, pada tahun 2016 jumlah kematian neonatus yaitu 32.007 per 100.000 kelahiran hidup dan pada tahun 2017 angka kematian neonatus yaitu 10.294 per 100.000 kelahiran hidup (Kemenkes RI, 2017).

Angka Kematian Neonatus (AKN) di Propinsi Jawa Tengah tahun 2015 berdasarkan laporan dari kabupaten/kota sebesar 9,4\% kelahiran hidup. Mengalami penurunan bila di bandingkan dengan AKN pada tahun 2016 sebesar 6,94\% kelahiran hidup (Dinkes Provinsi Jawa Tengah, 2016).

Di Kabupaten Tegal masalah utama penyebab kematian pada bayi dan balita adalah pada masa neonatus (bayi baru lahir umur 0-28

BHAMADA, JITK, Vol. 10, No. 1, April 2019 
hari), komplikasi yang menjadi penyebab kematian neonatus terbanyak adalah Berat Badan Lahir Rendah (BBLR) yaitu 0,32\%, Asfiksia yaitu $0,27 \%$ dan kelainan kongenital sebanyak 0,16\%. Menurut data Dinas Kesehatan Kabupaten Tegal pada tahun 2017 menunjukan bahwa 171 kematian neonatal yang terjadi (Dinkes Kabupaten Tegal, 2017).

\section{Upaya penurunan Angka Kematian} Neonatus (AKN) untuk meningkatkan derajat kesehatan yaitu menggunakan strategi program berbasis masyarakat. Menurut Peraturan Menteri Kesehatan no 39 tahun 2016 upayaupaya untuk mencegah Angka Kematian Neonatus diantaranya mengupayakan jaminan mutu kunjungan neonatal lengkap dan menguatkan kader posyandu (Kemenkes RI,2016).

Di Indonesia menurut data Kementrian Kesehatan Republik Indonesia pada tahun 2015 kunjungan neonatus lengkap yaitu $77,31 \%$, pada tahun 2016 yaitu $91,02 \%$ dan pada tahun 2017 yaitu 91,96\% dan pada tahun 2018 kunjungan neonatus lengkap yaitu $43,5 \%$ (Riskesdas, 2018).

Di Provinsi Jawa Tengah cakupan kunjungan neonatus lengkap pada tahun 2015 yaitu 96,8\%, sedangkan pada tahun 2016 mengalami penurunan menjadi $82,29 \%$ dan pada tahun 2017 mengalami peningkatan kembali menjadi 96,3\% tetapi hasil tersebut masih dibawah tahun 2015, dan pada tahun
2016 kunjungan neonatus lengkap belum mencapai cakupan target, dimana target cakupan yang harus di capai yaitu dengan prosentase target 88\% (Dinkes Provinsi Jawa Tengah, 2017).

Data yang didapatkan dari Puskesmas Kabupaten Tegal tahun 2015 mengenai kunjungan neonatus lengkap sebanyak 100\%, pada tahun 2016 kunjungan neonatus lengkap sebanyak 98,1\% dan pada tahun 2017 kunjungan neonatus lengkap sebanyak 99,7\% (Dinkes Provinsi Jawa Tengah, 2017).

Di Kabupaten Tegal puskesmas yang paling rendah cakupan kunjungan neonatus lengkap adalah puskesmas Lebaksiu, di tahun 2015 kunjungan neonatus lengkap mencapai 96,7\% dan di tahun 2016 kunjungan neonatus lengkap 96,2\% sedangkan pada tahun 2017 terjadi angka penurunan kunjungan neonatus lengkap yaitu 77,7\% (Dinkes Kabupaten Tegal 2017).Data dari Puskesmas Lebaksiu di bulan Januari sampai September 2018 cakupan kunjungan neonatus lengkap masih di bawah standar kunjungan neonatus lengkap yaitu 1,19\% sampai $17,9 \%$,sehingga belum mencapai target cakupan kunjungan neonatus lengkap, dimana target dari kunjungan neonatus lengkap yaitu $88 \%$ sehingga hal ini menjadi permasalahan terhadap kunjungan neonatus lengkap di kabupaten Tegal (Puskesmas Lebaksiu,2018).

Kunjungan neonatus dapat di lakukan di beberapa tempat di antaranya di Puskesmas, Bidan praktek mandiri (BPM) dan Posyandu 
yang terdapat di desa. Kegiatan posyandu sangat tergantung pada kader posyandu, keberadaan kader posyandu di butuhkan sebagai salah satu sistem penyelenggaraan pelayanan kebutuhan kesehatan dasar, kader posyandu merupakan ujung tombak pelayanan kesehatan yang merupakan kepanjangan tangan puskesmas (Nelli, 2015).

Di Puskesmas Lebaksiu jumlah kader kesehatan seluruhnya ada 285 orang tetapi yang aktif hanya 243 orang ( $85 \%)$ dan terdapat satu desa dengan keaktifan kader paling rendah adalah desa Timbangreja dengan 67\%, dimana kader terbilang aktif jika memenuhi target $80 \%$ sehingga hasil tersebut belum mencapai cakupan keaktifan kader (Ana,2015). Berdasarkan latar belakang tersebut, maka peneliti bermaksud melakukan penelitian untuk mengetahui Pengaruh Peran Aktif Kader Kesehatan Terhadap Kunjungan Neonatus Lengkap di Posyandu Wilayah Kerja Puskesmas Lebaksiu Kabupaten Tegal tahun 2018.

\section{METODE PENELITIAN}

Jenis penelitian ini adalah kuantatif, yang menggunakan sampel untuk mengambil kesimpulan pada populasi atau disebut dengan deskriptif korelatif. Pendekatan yang di gunakan dalam penelitian ini adalah pendekatan Retrospektif, berupa pengamatan terhadap peristiwa-peristiwa yang telah terjadi bertujuan untuk mencari faktor yang berhubungan dengan penyebab (Aziz, 2014). Dalam penelitian ini, data pokok yang di observasi adalah kunjungan neonatus lengkap, dan faktor yang perpengaruh terhadap kunjungan neonatus tersebut adalah keaktifan atau peran aktif kader kesehatan dalam pelayanan kunjungan neonatus di Posyandu.

Populasi dalam penelitian ini berjumlah 30 orang, yaitu kader kesehatan yang bertugas di Posyandu desa Timbangreja wilayah kerja Puskesmas Lebaksiu.

Teknik pengambilan sampel yang digunakan pada penelitian ini adalah Total sampling, dimana jumlah sampel sama dengan populasi, yaitu 30 orang kader kesehatan.

Analisis data dengan Kendall's tau yang digunakan untuk menguji apakah ada hubungan antara peran aktif kader kesehatan dengan kunjungan neonatus, dan perhitungan Regresi Logistik dengan $\alpha=0,05$ untuk mengetahui apakah ada pengaruh peran aktif kader kesehatan terhadap kunjungan neonatus. Pengolahan data dilakukan SPSS versi 16.

\section{HASIL PENELITIAN DAN PEMBAHASAN}

\section{A. HASIL PENELITIAN}

\section{Analisa Univariat}

a. Peran Aktif Kader Kesehatan

Tabel.1 distribusi frekuensi peran aktif kader kesehatan di Posyandu Desa Timbangreja wilayah kerja Puskesmas Lebaksiu Kabupaten Tegal Tahun 2018

\begin{tabular}{cccc}
\hline & Variabel & Frekuensi & $\%$ \\
\hline 1 & Aktif & 14 orang & $46,7 \%$ \\
\hline 2 & Kurang aktif & 16 orang & $53,3 \%$ \\
\hline & TOTAL & 30 orang & $100 \%$ \\
\hline
\end{tabular}

BHAMADA, JITK, Vol. 10, No. 1, April 2019 
Berdasakan tabel diatas dapat diketahui bahwa sebagian besar responden dalam penelitian ini kurang aktif dalam pelayanan kunjungan neonatus di Posyandu, yaitu 16 orang $(53,3 \%)$ dan 14 orang responden $(46,7 \%)$ aktif dalam kehadiran pelayanan kunjungan neonatus di Posyandu.

b. Kunjungan Neonatus Lengkap

Tabel 2. Kunjungan Neonatus (KN) Lengkap di Posyandu Desa Timbangreja Wilayah Kerja Puskesmas Lebaksiu Kabupaten Tegal Tahun 2018

\begin{tabular}{|c|c|c|c|}
\hline No & Variabel & Frekuensi & $\%$ \\
\hline 1 & $\begin{array}{l}\text { KN } \\
\text { Lengkap }\end{array}$ & 11 orang & $36,7 \%$ \\
\hline 2 & $\begin{array}{l}\text { KN } \\
\text { Tidak } \\
\text { Lengkap }\end{array}$ & 19 orang & $63,3 \%$ \\
\hline TOTAL & & 30 orang & $100 \%$ \\
\hline
\end{tabular}

Berdasarkan tabel diatas diketahui bahwa 63,3\% Posyandu dalam penelitian ini memiliki ketercapaian kunjungan neonatus tidak lengkap di Posyandu Desa Timbangreja Puskesmas Lebaksiu dan $36,7 \%$ Posyandu telah mencapai kunjungan neonatus lengkap.

\section{Analisa Bivariat}

Tabel 3. Peran Aktif Kader Kesehatan dengan Kunjungan Neonatus Lengkap di Posyandu Desa Timbangreja Wilayah Kerja Pusekesmas Lebaksiu Kabupaten Tegal Tahun 2018

\begin{tabular}{|c|c|c|c|c|c|c|c|c|}
\hline \multirow{2}{*}{$\begin{array}{l}\mathrm{N} \\
\mathrm{o}\end{array}$} & \multirow[t]{2}{*}{ Variabel } & \multicolumn{4}{|c|}{ Kunjungan Neonatus Lengkap } & \multirow{2}{*}{$\begin{array}{l}\text { To- } \\
\text { tal }\end{array}$} & \multirow[t]{2}{*}{$\%$} & \multirow{2}{*}{$\begin{array}{l}\text { P koefisiensi korelasi sebesar } 0,536 \text { (berada } \\
\text { valu } \\
\text { e diantara nilai koefisiensi korelasi } 0,51 \mathrm{~s} / \mathrm{d}\end{array}$} \\
\hline & & $\begin{array}{c}\text { KN } \\
\text { Lengkap }\end{array}$ & $\%$ & $\begin{array}{c}\text { KN } \\
\text { Tidak } \\
\text { Lengkap }\end{array}$ & $\%$ & & & \\
\hline 1 & $\begin{array}{c}\text { Kader } \\
\text { Aktif }\end{array}$ & 9 & $\begin{array}{l}30 \\
\%\end{array}$ & 5 & $\begin{array}{c}16,7 \\
\%\end{array}$ & 14 & $\begin{array}{c}46,7 \\
\%\end{array}$ & $\begin{array}{c}0,00 \\
4\end{array}$ \\
\hline
\end{tabular}

Pada tabel di atas menunjukkan bahwa,

Posyandu dengan peran kader kesehatan yang aktif lebih besar ketercapaian kunjungan neonatus lengkapnya (30\%) dibandingkan dengan ketercapaian kunjungan neonatus di Posyandu dengan peran kader kesehatan yang kurang aktif $(6 \%)$.

Tabel 4. Hubungan Peran Aktif Kader Kesehatan dengan Kunjungan Neonatus Lengkap di Posyandu Desa Timbangreja Wilayah Kerja Pusekesmas Lebaksiu Kabupaten Tegal Tahun 2018

\begin{tabular}{|lll|r|r|}
\hline \multicolumn{5}{c|}{ Correlations } \\
\hline & & $\begin{array}{r}\text { Peran } \\
\text { Kader }\end{array}$ & $\begin{array}{c}\text { Kunjungan } \\
\text { Neonatus }\end{array}$ \\
\hline $\begin{array}{l}\text { Kendall's } \\
\text { tau_b }\end{array}$ & Peran & $\begin{array}{l}\text { Correlation } \\
\text { Kader }\end{array}$ & 1.000 & $.536^{* *}$ \\
& & Sig. (2-tailed) &. & .004 \\
& $\mathrm{~N}$ & 30 & 30 \\
\cline { 2 - 5 } & $\begin{array}{l}\text { Kunjungan } \\
\text { Neonatus }\end{array}$ & Correlation \\
& & Sig. (2-tailed) & .004 & 1.000 \\
& $\mathrm{~N}$ & 30 & 30 \\
& &
\end{tabular}

**. Correlation is significant at the 0.01 level (2-tailed).

Berdasarkan perhitungan Kendall's tau dengan $\alpha=0,05$ diperoleh nilai $\mathrm{p}$ sebesar 0,04 . Karena nilai $\mathrm{p}<\alpha$ berarti secara statistik hasil pengujian signifikan, atau menolak Ho, maka dapat disimpulkan bahwa ada hubungan peran aktif kader kesehatan dengan kunjungan neonatus lengkap. Nilai

\begin{tabular}{|c|c|c|c|c|c|c|c|c|}
\hline 2 & Kader & 2 & $\begin{array}{c}6,7 \\
\%\end{array}$ & 14 & $\begin{array}{c}46,7 \\
\%\end{array}$ & 16 & $\begin{array}{c}53,3 \\
\%\end{array}$ & \\
Kurang & & & & & & & \\
\hline TKtif & 11 & $\begin{array}{c}36,7 \\
\%\end{array}$ & 19 & $\begin{array}{c}63,3 \\
\%\end{array}$ & 30 & $\begin{array}{c}100 \\
\%\end{array}$ & \\
\hline
\end{tabular}


yang kuat. Dan tanda ** menunjukkan hubungan yang terbentuk signifikan pada angka signifikasi sebesar 0,01. Tabel di atas juga menunjukkan arah hubungan antar varibel bersifat positif dilihat dari koerfisien korelasi sebesar 0,536.

Mengacu pada ketiga interpretasi dalam uji di atas maka dapat disimpilkan bahwa " Hubungan antara peran aktif kader kesehatan dengan kunjungan neonatus lengkap di Posyandu Desa Timbangreja wilayah kerja Puskesmas Lebaksiu Kabupaten Tegal tahun 2018 adalah signifikan, kuat dan searah."

Tabel 5. Pengaruh peran aktif kader kesehatan terhadap kunjungan neonatus lengkap di Posyandu Desa Timbangreja wilayah kerja Puskesmas Lebaksiu Kabupaten Tegal tahun 2018

\section{Variables in the Equation}

\begin{tabular}{|ll|c|c|c|c|c|c|}
\hline & & B & S.E. & Wald & df & Sig. & $\operatorname{Exp(B)}$ \\
\hline Step & Kunjungan & & & & & & \\
$1^{\text {a }}$ & Neonatus & 2.534 & .939 & 7.274 & 1 & .007 & 12.600 \\
& & & & & & & \\
& Constant & -1.030 & .521 & 3.906 & 1 & .048 & .357 \\
\hline
\end{tabular}

Hasil uji korelasi dalam penelitian ini menyatakan bahwa ada hubungan antara peran aktif kader kesehatan dengan kunjungan neonatus lengkap, dan hasil uji pengaruh dalam tabel di atas didapatkan nilai Sig. 0,007, hal tersebut berarti ada pengaruh peran aktif kader kesehatan terhadap kunjungan neonatus lengkap di Posyandu Desa Timbangreja wilayah kerja Puskesmas Lebaksiu Kabupaten Tegal tahun
2018, dan kedua varibel tersebut saling mempengaruhi, dengan nilai B sebesar 12,6 yang berarti bahwa kader yang aktif akan berpengaruh 12,6 kali lebih besar terhadap kelengkapan kunjungan neonates dibandingkan dengan kader kesehatan yang kurang aktif.

\section{B. PEMBAHASAN}

Berdasarkan hasil penelitian, diketahui bahwa sebagian besar responden, yaitu kader kesehatan belum berperan aktif dalam pelaksanaan Posyandu desa Timbangreja, sebanyak 53,3\%, dimana peran aktif kader adalah kehadiran kader kesehatan dalam setiap kegiatan Posyandu minimal delapan kali dalam setahun. Dan Posyandu di desa Timbangreja yang belum tercapai kunjungan neonatus lengkapnya sebanyak 63,3\%.

Menurut penelitian Diah tahun 2015 yang berfokus pada pemberdayaan kader Posyandu, mengungkapkan bahwa sebagian besar kader memiliki pengetahuan dasar yang baik, tetapi ketrampilan dalam bersosialisasi masih kurang. Hal tersebut mendukung dengan penelitian ini, sehingga perlu diupayakan pelatihan berbicara di depan umum bagi kader kesehatan dan merancang atau mengembangkan media komunikasi yang sesuai dengan latar belakang budaya setempat, agar muncul kesadaran kader kesehatan untuk 
mensosialisasikan dan melestarikan program Posyandu, khususnya terkait dengan tujuan tercapainya target kunjungan neonatus lengkap di wilayah tersebut.

Berdasarkan penelitian Catherine tahun 2016 tentang efektivitas program kunjungan rumah bayi baru lahir oleh anggota masyarakat terlatih di Ghana dan Asia Selatan, yang didapatkan hasil bahwa angka kematian neonatal berkurang sebesar $12 \%$. Penelitian tersebut menyebutkan bahwa intervensi kunjungan rumah atau pengawasan pada bayi oleh masyarakat sukarelawan berbasis komunitas efektif menurunkan kematian pada neonatal. Sehingga temuan ini mendapatkan dukungan dari WHO yang merekomendasikan kunjungan rumah pada bayi baru lahir. Hasil tersebut senada dengan penelitian ini, dimana kunjungan bayi baru lahir yang dilakukan oleh masyarakat sukarelawan yaitu kader kesehatan, dapat dilaksanakan di Posyandu secara kontinyu, sehingga diharapkan dapat menurunkan angka morbiditas maupun mortalitas pada neonatus. Hal tersebut didukung pula dengan penelitian Flavia pada tahun 2016 dan tahun 2017 di Brasil yang menunjukkan bahwa kunjungan pada bayi dapat membawa perasaan positif, sehingga meminimalkan ketakutan dan keraguan seorang ibu, serta mendukung pada perilaku keibuan.

\section{KESIMPULAN}

1. Sebagian besar responden dalam penelitian ini kurang aktif dalam pelayanan kunjungan neonatus di Posyandu, yaitu 16 orang $(53,3 \%)$ dan 14 orang responden $(46,7 \%)$ aktif dalam kehadiran pelayanan kunjungan neonatus di Posyandu.

2. Sebagian besar Posyandu dalam penelitian ini memiliki ketercapaian kunjungan neonatus tidak lengkap di Posyandu Desa Timbangreja Puskesmas Lebaksiu sebesar 63,3\% dan $36,7 \%$ Posyandu telah mencapai kunjungan neonatus lengkap.

3. Posyandu dengan peran kader kesehatan yang aktif lebih besar ketercapaian kunjungan neonatus lengkapnya (30\%) dibandingkan dengan ketercapaian kunjungan neonatus di Posyandu dengan peran kader kesehatan yang kurang aktif (6\%).

4. Hasil analisis bivariat dengan menggunakan Kendall's tau, menunjukkan ada hubungan antara peran aktif kader kesehatan dengan kunjungan neonatus lengkap di Posyandu Desa Timbangreja wilayah kerja Puskesmas Lebaksiu Kabupaten Tegal tahun 2018 yang signifikan, kuat dan searah.

5. Hasil uji pengaruh dengan menggunakan Regresi Logistik, menunjukkan bahwa ada pengaruh antara peran aktif kader kesehatan terhadap kunjungan neonatus lengkap di 
Posyandu Desa Timbangreja wilayah kerja Puskesmas Lebaksiu Kabupaten Tegal tahun 2018.

\section{SARAN}

1. Bagi tenaga kesehatan

Diperlukan upaya peningkatan pelayanan kunjungan neonatal dalam Posyandu khususnya bagi kader kesehatan dan tim kesehatan lainnya termasuk bidan desa, baik dari segi keaktifan kehadiran, ketrampilan pelayanan, maupun pengetahuan, dan upaya pendidikan kesehatan yang adekuat tentang pentingnya kunjungan neotaus sehingga semua ibu yang baru melahirkan dan keluarganya termotivasi untuk melakukan kunjungan neonatus dengan teratur. Dimana pelayanan asuhan neonatus tersebut dapat terintegrasi dalam kegiatan Posyandu balita, yang pelaksanaan dan frekuensinya disesuaikan dengan standar dan program dari pemerintah. Sehingga seluruh neonatus mendapatkan asuhan yang efektif dan komprehensif sehingga dapat menurunkan angka morbiditas maupun mortalitas pada neonatus.

2. Unit pelayanan kesehatan

Diperlukan upaya untuk menyediakan sarana dan prasarana yang memadai dan sesuai standar untuk pelaksanaan kunjungan neonatus Posyandu di wilayah kerja masing-masing Puskesmas. Unit pelayanan kesehatan seperti Posyandu juga perlu upaya meningkatkan kualitas tenaga pendukung kegiatan seperti kader kesehatan dan tenaga kesehatan khususnya bidan, sebagai penanggung jawab kegiatan Posyandu, dengan mengirimkan tenaga profesional tersebut mengikuti pelatihan maupun seminar terkini mengenai asuhan neonatus dalam program kunjungan neonatus maupun hal-hal terkait, sehingga dapat diaplikasikan dan dimanfaatkan oleh seluruh kader sesuai dengan wilayahnya, dan oleh ibu atau keluarga yang memiliki neonatus.

3. Bagi peneliti lain

Perlu dilakukan penelitian yang sejenis dengan responden penelitian adalah kader kesehatan, bidan maupun ibu yang memiliki neonatus yang lain, yang berada diwilayah kerja yang berbeda.

\section{DAFTAR PUSTAKA}

Kemenkes RI. 2015. Profil Kesehatan Indonesia. Jakarta: Kemenkes RI

Kemenkes RI. 2012.Profil Kesehatan Indonesia. Jakarta: Kemenkes RI

Kemenkes RI. 2016. Profil Kesehatan Indonesia. Jakarta: Kemenkes RI

Kemenkes RI. 2017. Profil Kesehatan Indonesia. Jakarta: Kemenkes RI

Dinas Kesehatan Provinsi Jawa Tengah. 2016. Profil Kesehatan Provinsi Jawa Tengah Tahun 2016. Semarang: Dinas Kesehatan Provinsi Jawa Tengah.

Dinas Kesehatan Kabupaten Tegal. 2017. Profil Kesehatan Kabupaten Tegal Tahun 2017. 
Tegal: Dinas Kesehatan Kabupaten Tegal

Kemenkes RI. Permenkes RI tahun 2016.

Peraturan Menteri Kesehatan Indonesia.

Jakarta: Kemenkes RI

Kemenkes RI. 2018. Hasil Utama Riskesdas. Jakarta: Kemenkes RI

Dinas Kesehatan Provinsi Jawa Tengah. 2017.

Profil Kesehatan Provinsi Jawa Tengah

Tahun 2017. Semarang: Dinas Kesehatan Provinsi Jawa Tengah.

Puskesmas Lebaksiu. 2018. Laporan Kunjungan Neonatus Pertahun.Tegal.

Nelly, Malahayati. 2015. Hubungan Peran

Kader dan Dukungan Keluarga Terhadap

Rendahnya Kunjungan Bayi dan Balita

Ke Posyandu di Desa Buket Kecamatan Sungai Raya Kabupaten Aceh Timur. Diakses 12 Desember 2018.

Didapat diakses : www.StikesBinusa.ac.id Ana, 2015. Keaktifan Kader Posyandu di Wilayah Kerja Puskesmas Slawi Diakses

21 November 2015. www.Udinus.com

Aziz, Alimul. 2014. Metode Penelitian

Kebidanan dan Teknik Analisa Data.

Jakarta: Salemba Medika

Diah Nirwana, Maya, Dkk. 2015. The Cadre of

Integrated Health Service Post

(Posyandu) as an Agent in the

Socialization of Cervical Cancer

Prevention in Malang Regency,

Indonesia: A Cultural Approach. Procedia

- Social and Behavioral Sciences. Volume

211, 25 November 2015, Pages 681-687.

https://doi.org/10.1016/j.sbspro.2015.11.1

$\underline{03}$

Catherine Pitt, et all. 2016. The Lancet Global

Health. Volume 4, Issue 1, January 2016,

Pages e45-e56.

https://doi.org/10.1016/S2214-

109X(15)00207-7. Diakses tgl 20 Januari

2019
Flavia da Veiga Ued, et all. 2019. Perception of Mothers when Visiting their child in the neonatal unit for the first time.

https://www.researchgate.net/publication/3 30889885_Perception_of_mothers_when_v isiting_their_child_in_the_neonatal_unit_fo r_the_first_time. Universidade Federal do Triângulo Mineiro, Uberaba, MG, Brasil. DOI: $\quad 10.1590 / 2177-9465$-ean-2018-0249. Article (PDF Available) January 2019. 